\title{
A Numerical Investigation on Scaling Rolling Friction Effects in Shaking Table Model Tests
}

\author{
Shanshan Li, ${ }^{1}$ Biao Wei $\mathbb{D}^{2,3}$ Chengjun Zuo $\mathbb{D}^{2,3}$ and Xuhui He $\mathbb{D}^{2,3}$ \\ ${ }^{1}$ School of Intelligent Manufacturing, Jiangsu Vocational Institute of Architectural Technology, Xuzhou 221116, China \\ ${ }^{2}$ School of Civil Engineering, Central South University, Changsha 410075, China \\ ${ }^{3}$ National Engineering Laboratory for High Speed Railway Construction, Changsha 410004, China
}

Correspondence should be addressed to Biao Wei; weibiao@csu.edu.cn

Received 19 April 2019; Revised 8 July 2019; Accepted 9 September 2019; Published 3 October 2019

Academic Editor: Gloria Terenzi

Copyright ( $\odot 2019$ Shanshan Li et al. This is an open access article distributed under the Creative Commons Attribution License, which permits unrestricted use, distribution, and reproduction in any medium, provided the original work is properly cited.

Friction action is a damping mechanism used in civil structures. It often works together with traditional viscous damping. The rolling friction action is nonlinear, and its scaling process in shaking table model tests is suspect, especially in cases of working in combination with traditional viscous dampers. To solve the problem, a numerical model of simplified viscous damper-Coulomb friction base isolation system was scaled. The comparison between the scaled and the prototype model results showed two important factors that influence the scaling of rolling friction action. One factor is the unscaled gravity acceleration, which results in an adverse friction force and seismic responses of scaled models. These adverse seismic responses can be improved by changing the friction coefficient to correct for the abovementioned adverse friction force in the dynamic equation. Another factor is the friction variation in space, causing adverse scaled seismic responses. These adverse seismic responses can be improved by moving the variable friction positions along the scaled size of contact surface. The influence of the above two factors can be weakened by increasing the traditional viscous damping component and the earthquake intensity.

\section{Introduction}

Rolling and sliding friction devices have been widely used in the seismic isolation of civil structures. These friction devices are simple [1] but have an acceleration isolation efficiency of 50-90\% [2]. Ismail and Casas invented a roll-n-cage (RNC) device [3] to protect bridge structures near faults $[4,5]$. Wang and Hwang et al. [6] and Guerreiro et al. [7] used a sloped multiroller device to isolate equipment and light structures during earthquakes. Jangid and Londhe used elliptical rods [8] or rolling rod-spring devices [9] to reduce the seismic residual displacement of the whole building structure, while Cui [10] used damped balls to isolate only a building floor during earthquakes. Some sliding friction bearings, such as the American Friction Pendulum Systems [11] and European Curved Surface Sliders [12, 13], were used to support large-span bridges, heavy buildings, and liquid storage tanks and had displacement capacities of over $1 \mathrm{~m}$.
These sliding friction bearings had many advantages, including a high bearing capacity, a large displacement capacity, good durability, satisfactory recentering, and variable natural vibration periods controlled by the slide radius. However, the sliding radius implied the vertical vibration of structure when isolating the horizontal earthquakes. And the American Friction Pendulum System and European Curved Surface Sliders were not applicable to the structures that were sensitive to the vertical vibration.

Shaking table model tests are widely used to improve these kinds of devices and their application. Due to the relatively small load capacities of common shaking tables, light structures and isolation devices can directly use the prototype model for analysis, while heavy structures and isolation devices have to use scaled models in shaking table tests. Friction action is nonlinear, and its scaling process in shaking table model tests is widely suspect. It is necessary to carry out a numerical analysis on these kinds of problems 
before a practical shaking table model test can be developed. However, the numerical analysis is still required to address the following questions.

The first question is can the numerical method predict the seismic responses of friction-based isolation systems? Harvey and Gavin found that a uniaxial numerical model was unable to predict the chaotic responses of a four-bowl supported system [14]. However, they later found that even a reducedorder numerical model was validated as correct when compared with the test results [15], when all of the initial conditions were fully considered [16]. Ortiz et al. also found that the numerical results could be close to the experimental results for a rolling-bearing supported building [17]. Ou et al. [18] and Lee et al. [19] found a numerical method, being different from AASHTO (American Association of State Highway and Transportation Officials), to predict the seismic behavior of roller bearings used in highway bridges. Most of the above references identified that the numerical method was an effective tool at least in predicting the seismic responses of Coulomb friction systems.

The second question is what kind of friction can be analyzed by the numerical analysis method? The rolling friction has small friction coefficient values [20], while the sliding friction has larger values [21]. However, super lubrication technology can also reduce the sliding friction coefficient to a very small value, such as 0.001 [22]. However, the friction coefficient is not always constant but changes in space or with time $[23,24]$. The rolling friction action, changing only in space, is Coulomb friction, which is easily simulated by a numerical model $[25,26]$. With respect to the sliding friction action changing with time, the thermodynamics, the sliding velocity, the contact pressure, the damage, and other factors have to be considered to determine the variable friction coefficient on the contact surface $[27,28]$. It is incorrect to numerically simulate such complex sliding friction action by using the Coulomb friction model. In practice, the rolling friction is a widely used isolation mechanism in seismic engineering. Therefore, this paper analyzes the rolling friction only, when simulated with the Coulomb friction model.

The third question is can the friction action be equivalent to the traditional viscous damper? Although the traditional dynamics equation usually assumed all energy dissipation components to the simple viscous damper, their mechanics were different. For example, the friction action not only dissipated energy but also locked the relative motion. However, the general viscous damper dissipated energy more efficiently during earthquakes but did not hinder the recentering of the structure after earthquakes in a pseudodynamic test by Sorace and Terenzi [29]. Chung and Kao et al. [30] found that there were not too many energy dissipation components when determining optimum damping. However, a viscous damper usually needs to be added to reduce the seismic displacement response, when a small friction coefficient is adopted to isolate the earthquake energy. Therefore, the friction action and the viscous damper should be simulated, respectively, when they work together. For example, Sorace and Terenzi [31] rigorously modelled the frictional contact and the viscous damper in a concrete building, and used the viscous component to successfully retrofit the structure.

The fourth question is can all of the factors determining the friction force be rigorously scaled? The factors include the friction coefficient and the structural gravity [32]. As the friction coefficient is a dimensionless quantity, it does not need to be scaled in theory. However, different friction coefficients are always distributed along the length of contact surface, which are described as the Coulomb friction changing in space in the second question [33]. There is a new question: should the positions of specific friction coefficients move with the scaled length of contact surface? Another factor is that the structural gravity cannot be scaled on the common shaking tables [34]. Although the external bars were placed to equivalently scale the structural gravity by adding the prestress force, the force changed during a dynamic test [35].

The first three questions are answered; however, the fourth question needs to be studied. As to study the fourth question, a simplified viscous damper-Coulomb friction base isolation system was obtained by joining a rolling action and a viscous damper. The rolling action could isolate and dissipate the seismic energy during earthquakes. As to further reduce the structural relative displacement, a viscous damper was added to the Coulomb friction system to dissipate the seismic energy more efficiently around the center of contact surface. Based on the answers of the first three questions, the fourth question was solved in this paper, by numerically scaling the simplified viscous damper-Coulomb friction base isolation system. The results of scaled models were compared with those of the prototype model. The comparison results provided the answer on how to scale the uneven friction distribution and the structural gravity, in the fourth question.

\section{Viscous Damper-Coulomb Friction Models and Calculations}

2.1. Structural Models. Figure 1 shows a viscous damperCoulomb friction isolation system. The linear viscous damper has a viscous damping constant $C$, the rolling friction has a Coulomb fricion coefficient $\mu$, and the structure has a mass $m . a_{\mathrm{e}}$ and $a_{\mathrm{s}}, v_{\mathrm{e}}$ and $v_{\mathrm{s}}$, and $d_{\mathrm{e}}$ and $d_{\mathrm{s}}$ are defined as the absolute acceleration, velocity, and displacement of the ground and structure, respectively. And the structural dynamic behavior is expressed by the equation $m a_{\mathrm{s}}=\left[ \pm \mu m g+C\left(v_{\mathrm{e}}-v_{\mathrm{s}}\right)\right]$.

The rolling action on the flat surface can isolate the seismic energy during earthquakes and can avoid the structural vertical vibration that happens in the cases using the American Friction Pendulum Systems and European Curved Surface Sliders. When the isolated structure moves due to the rolling action, the rolling friction $\pm \mu m g$ is expected to dissipate the seismic energy to avoid a too large displacement relative to the ground. However, a large relative displacement always exists, if only the rolling friction dissipates the seismic energy at the interface. It is necessary to add a viscous damper to the system, as shown in Figure 1. The viscous damper can dissipate the seismic energy more 


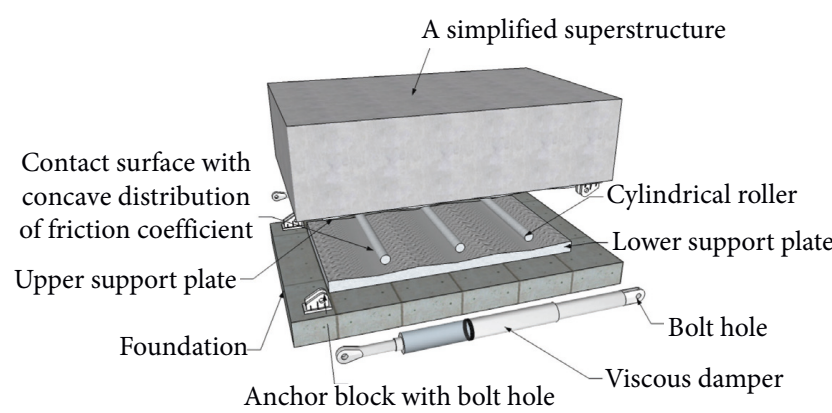

Figure 1: Viscous damper-Coulomb friction isolation system.

efficiently, especially when the large relative velocity $\left(v_{\mathrm{e}}-v_{\mathrm{s}}\right)$ happens around the center of contact surface. After most of the seismic energy is dissipated around the center of contact surface by the viscous damper, the residual motion energy is continuously dissipated by the rolling friction. Therefore, the structural relative displacement of the viscous damperCoulomb friction isolation system will be much smaller than that of the Coulomb friction isolation system.

In Figure 1, the isolated structure is modelled as a single degree of freedom system to avoid the influence of higher order vibration modes on the study topic of this paper [22]. Its mass $m$ is set to be $300 \mathrm{t}$. The damping constant $C$ is simply assumed to be 100 and $200 \mathrm{kN} \cdot \mathrm{s} / \mathrm{m}$, respectively. The equivalent damping ratio is less than $25 \%$, if the structural natural vibration periods is less than $4.5 \mathrm{~s}$. In theory, the viscous damping force is $F_{\mathrm{d}}=C \operatorname{sgn}(v)|v|^{\alpha}$, where $v$ is the relative velocity $\left(v_{\mathrm{e}}-v_{\mathrm{s}}\right)$ and $\alpha$ is the damping exponent. $\alpha$ is usually adopted in the range 0.1 2 and commonly has the values $0.1 \sim 0.5$. However, $\alpha$ is temporarily adopted as 1.0 in this paper, and thus, the equation $F_{\mathrm{d}}=\operatorname{Csgn}(v)|v|^{\alpha}$ is simplified as $F_{\mathrm{d}}=C\left(v_{\mathrm{e}}-v_{\mathrm{s}}\right)$. The simplification can mitigate the influence of the complex scaling of viscous damper, on the study topic of this paper.

Based on the discussion in the introduction, this paper only considers Coulomb friction changing in space. The rolling friction coefficient depends on the stiffness of materials on the flat contact surface. When the common alloy materials become softer, the rolling friction coefficient increases from 0.005 to 0.5 . In Figure 1, six concave friction distributions were set, by assuming the use of softer alloy materials when the roller rolled far away from the initial position. The concavely distributed friction force was validated to improve the seismic isolation efficiency [26]. In the concave friction distributions, the friction coefficient has the smallest value of $\mu=0.005$ in the central position and increases when the structure moves relative to the central position. The friction coefficient increment per meter is defined as the increment ratio $R$ and is assumed as $0,0.01$, $0.02,0.03,0.04$, and $0.05 \mathrm{~m}^{-1}$, respectively, in this paper.

In the six concave friction distributions above, a uniform friction distribution pattern exists for $R=0 \mathrm{~m}^{-1}$, and it is further divided into three cases considering friction variation coefficients on the contact surface, as shown in Figure 2:

(1) Case 1 is assumed to be an absolutely uniform friction distribution with a friction variation coefficient of 0 . It

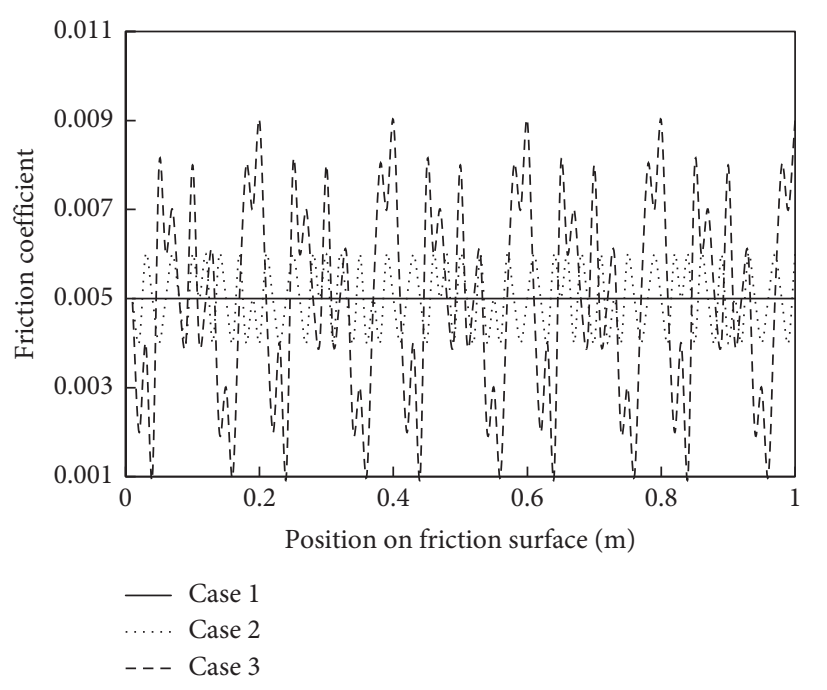

Figure 2: Three friction distributions (average value: 0.005).

implies that the alloy materials are the same at any of the different positions on the flat contact surface. It is an absolutely ideal or impossible case.

(2) Case 2 is assumed to be a slightly nonuniform friction distribution on a well-constructed contact surface. The friction coefficient has a variation range of $-0.001 \sim 0.001$ and an average value of 0.005 . When the different friction coefficients at different positions on the flat contact surface are compared with the average value, the standard deviation of friction coefficient is 0.000815 . Therefore, the friction variation coefficient is $0.000815 / 0.005=0.163$ in space. It implies that the alloy materials are a little different at different positions on the flat contact surface.

(3) Case 3 is assumed to be a similar nonuniform friction distribution as case 2 but on a relatively poorly constructed contact surface. The friction variation coefficient increases to $0.002355 / 0.005=0.471$ in space because the friction coefficient has a large variation range of $-0.004 \sim 0.004$, an average value of 0.005 , and a standard deviation of 0.002355 . It implies that the alloy materials are considerably different at different positions on the flat contact surface.

2.2. Ground Motion. In Figure 3, one Chinese seismic spectrum (JTJ 004-89) [36] is assumed as the target spectrum of the viscous damper-Coulomb friction system. This target spectrum is well-matched by the mean spectrum of 20 ground motions, selected and scaled from the Pacific Earthquake Engineering Research Center database. Following the selection, the two processes are carried out on these 20 ground motions:

(1) Some scaling factors are used to change the PGA of mean spectrum to $0.05,0.1,0.2,0.4$, and $0.8 \mathrm{~g}$, respectively. The 20 ground motions are scaled as the ground motion inputs of the prototype model, by using the same scaling factors. 


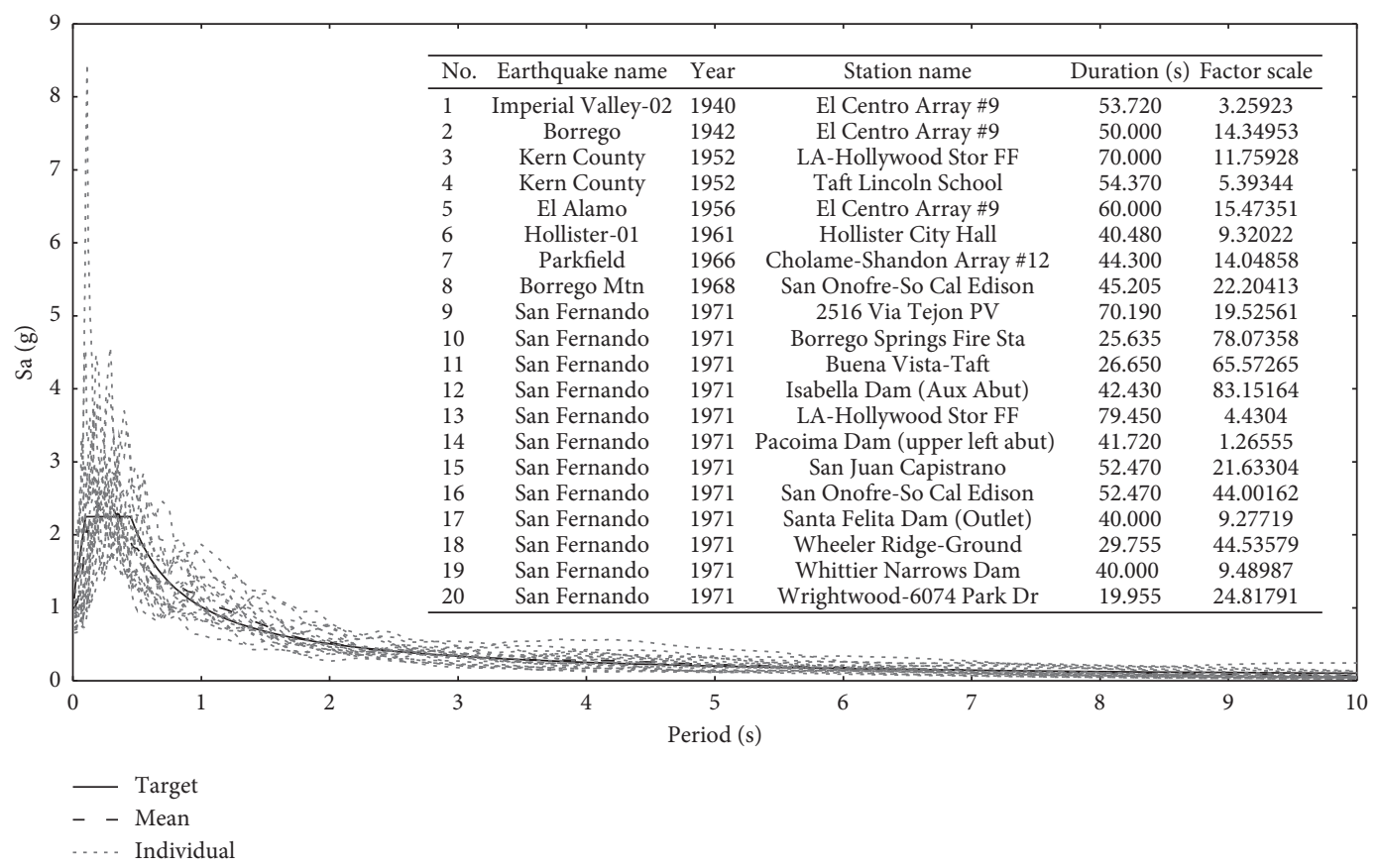

FIgURE 3: Target spectrum, mean spectrum, and individual earthquake spectra.

(2) The scaling factors in Tables 1 and 2 are then used to further scale the duration and PGA of the above scaled ground motions. These further scaled ground motions are the input to the scaled models of viscous damper-Coulomb friction system.

2.3. Scaling the Numerical Models. The dimensional analysis [37], described in the "equation" column in Tables 1 and 2, is used to scale the structural parameters in a numerically simulated shaking table test. Tables 1 and 2 have 7 scales, respectively, including the prototype and scaled models. The scaled models in Table 1 adopt the same density as the prototype model, while that in Table 2 scales the density to satisfy the load capacity of shaking table. However, the scaled density implies a positive or negative extra mass added to the scaled model.

As discussed in the introduction, the gravity acceleration is scalable in theory but cannot be rigorously scaled in practice. The unscaled gravity acceleration will cause an incorrect gravity force in the shaking table test, which will influence the seismic responses of scaled models. Therefore, both scaled and unscaled gravity accelerations are considered in this paper, and their scaling factors are listed in the rows "gravity acceleration 1" and "gravity acceleration 2", in Tables 1 and 2, respectively. The unscaled gravity acceleration is used to study on the factor of gravity distortion that influences the scaling of rolling friction action, while the scaled counterpart is used to investigate on other influence factors by assuming the scalable gravity acceleration.

2.4. Calculation Cases and Methods. There were 40000 calculation cases considering every possible combination of
1 structural mass, 2 damping constants, 8 friction distributions, 25 model scales, and 20 ground motion recordings with 5 different PGA.

The above cases were calculated using a self-compiled computer program. In the computer program, $a_{\mathrm{e}}$ and $a_{\mathrm{s}}, v_{\mathrm{e}}$ and $v_{\mathrm{s}}$, and $d_{\mathrm{e}}$ and $d_{\mathrm{s}}$ were the absolute acceleration, velocity, and displacement of the ground and structure, respectively. Two different motion cases were defined based on the comparison between $v_{\mathrm{e}}$ and $v_{\mathrm{s}}$ :

(1) $v_{\mathrm{e}}>v_{\mathrm{s}}$ or $v_{\mathrm{e}}<v_{\mathrm{s}}$ indicated that the structure moved slower or faster than the ground and had an inertia force of $\left[ \pm \mu m g+C\left(v_{\mathrm{e}}-v_{\mathrm{s}}\right)\right]$.

(2) $v_{\mathrm{e}}=v_{\mathrm{s}}$ implied that the structure moved with the same velocity and acceleration as the ground. This was a temporary motion state, and the next motion state was predicted by comparing $\left|a_{\mathrm{e}}\right|$ and $\mu g$ as follows:

(1) When $\left|a_{\mathrm{e}}\right| \leq \mu g$, the inertia force was too small to trigger the structural relative movement, and the structure still moved with the same velocity and acceleration as the ground

(2) When $\left|a_{\mathrm{e}}\right|>\mu \mathrm{g}$, the inertia force was so large that there was a relative structural movement, and the value of inertia force was $\left[ \pm \mu m g+C\left(v_{\mathrm{e}}-v_{\mathrm{s}}\right)\right]$

The cases (1) and (2)(2) were defined as the rolling state, and the isolated structure was subjected to the force of $\left[ \pm \mu m g+C\left(v_{\mathrm{e}}-v_{\mathrm{s}}\right)\right]$. Based on the Euler-Gauss method, the relationship between the structural acceleration, velocity, and displacement could be easily obtained. Finally, the structural movement during the next time could be calculated based on that of the previous time. When $\left|\left(v_{\mathrm{s}}-v_{\mathrm{e}}\right)+\left(C\left(v_{\mathrm{e}}-v_{\mathrm{s}}\right) \Delta t_{i} / m\right)\right| \leq \mu g \Delta t_{i}$ and 
TABLE 1: Scale parameters without scaling density.

\begin{tabular}{|c|c|c|c|c|c|c|c|c|c|}
\hline \multirow{2}{*}{ Physical parameter } & \multirow{2}{*}{ Units } & \multirow{2}{*}{ Equation } & \multicolumn{7}{|c|}{ Scale } \\
\hline & & & $1: 1$ & $1: 4$ & $1: 7$ & $1: 10$ & $1: 13$ & $1: 16$ & $1: 19$ \\
\hline Length & $\mathrm{m}$ & $1 / L$ & 1 & $1 / 4$ & $1 / 7$ & $1 / 10$ & $1 / 13$ & $1 / 16$ & $1 / 19$ \\
\hline $\begin{array}{l}\text { Friction increment ratio (friction coefficient } \\
\text { increment per meter) }\end{array}$ & $1 / \mathrm{m}$ & $L$ & 1 & 4 & 7 & 10 & 13 & 16 & 19 \\
\hline Elastic modulus & $\mathrm{kN} / \mathrm{m}^{2}$ & 1 & 1 & 1 & 1 & 1 & 1 & 1 & 1 \\
\hline Stress & $\mathrm{kN} / \mathrm{m}^{2}$ & 1 & 1 & 1 & 1 & 1 & 1 & 1 & 1 \\
\hline Density & $\mathrm{t} / \mathrm{m}^{3}$ & $D$ & 1 & 1 & 1 & 1 & 1 & 1 & 1 \\
\hline Mass & $\mathrm{t}$ & $D / L^{3}$ & 1 & 0.0156 & 0.00292 & 0.001 & 0.000455 & 0.000244 & 0.000146 \\
\hline Force & $\mathrm{kN}$ & $1 / L^{2}$ & 1 & 0.0625 & 0.0204 & 0.01 & 0.00592 & 0.00391 & 0.00277 \\
\hline Damping constant & $\mathrm{kN} \cdot \mathrm{s} / \mathrm{m}$ & $D^{0.5} / L^{2}$ & 1 & 0.0625 & 0.0204 & 0.01 & 0.00592 & 0.00391 & 0.00277 \\
\hline Time & $\mathrm{s}$ & $D^{0.5} / L$ & 1 & 0.25 & 0.143 & 0.1 & 0.0769 & 0.0625 & 0.0526 \\
\hline Velocity & $\mathrm{m} / \mathrm{s}$ & $1 / D^{0.5}$ & 1 & 1 & 1 & 1 & 1 & 1 & 1 \\
\hline Acceleration & $\mathrm{m} / \mathrm{s}^{2}$ & $\mathrm{~L} / D$ & 1 & 4 & 7 & 10 & 13 & 16 & 19 \\
\hline Gravity acceleration 1 & $\mathrm{~m} / \mathrm{s}^{2}$ & $L / D$ & 1 & 4 & 7 & 10 & 13 & 16 & 19 \\
\hline Gravity acceleration 2 & $\mathrm{~m} / \mathrm{s}^{2}$ & 1 & 1 & 1 & 1 & 1 & 1 & 1 & 1 \\
\hline
\end{tabular}

TABLE 2: Scale parameters with scaling density.

\begin{tabular}{|c|c|c|c|c|c|c|c|c|c|}
\hline \multirow{2}{*}{ Physical parameter } & \multirow{2}{*}{ Units } & \multirow{2}{*}{ Equation } & \multicolumn{7}{|c|}{ Scale } \\
\hline & & & $1: 1$ & $1: 4$ & $1: 7$ & $1: 10$ & $1: 13$ & $1: 16$ & $1: 19$ \\
\hline Length & $\mathrm{m}$ & $1 / L$ & 1 & $1 / 4$ & $1 / 7$ & $1 / 10$ & $1 / 13$ & $1 / 16$ & $1 / 19$ \\
\hline $\begin{array}{l}\text { Friction increment ratio (friction coefficient } \\
\text { increment per meter) }\end{array}$ & $1 / \mathrm{m}$ & $L$ & 1 & 4 & 7 & 10 & 13 & 16 & 19 \\
\hline Elastic modulus & $\mathrm{kN} / \mathrm{m}^{2}$ & 1 & 1 & 1 & 1 & 1 & 1 & 1 & 1 \\
\hline Stress & $\mathrm{kN} / \mathrm{m}^{2}$ & 1 & 1 & 1 & 1 & 1 & 1 & 1 & 1 \\
\hline Density & $\mathrm{t} / \mathrm{m}^{3}$ & $D$ & 1 & 0.522 & 2.800 & 8.163 & 17.934 & 33.436 & 55.990 \\
\hline Mass & $\mathrm{t}$ & $D / L^{3}$ & 1 & 0.00816 & 0.00816 & 0.00816 & 0.00816 & 0.00816 & 0.00816 \\
\hline Force & $\mathrm{kN}$ & $1 / L^{2}$ & 1 & 0.0625 & 0.0204 & 0.01 & 0.00592 & 0.00391 & 0.00277 \\
\hline Damping constant & $\mathrm{kN} \cdot \mathrm{s} / \mathrm{m}$ & $D^{0.5} / L^{2}$ & 1 & 0.0452 & 0.0341 & 0.0286 & 0.0251 & 0.0226 & 0.0207 \\
\hline Time & s & $D^{0.5} / L$ & 1 & 0.181 & 0.239 & 0.286 & 0.326 & 0.361 & 0.394 \\
\hline Velocity & $\mathrm{m} / \mathrm{s}$ & $1 / D^{0.5}$ & 1 & 1.384 & 0.598 & 0.350 & 0.236 & 0.173 & 0.134 \\
\hline Acceleration & $\mathrm{m} / \mathrm{s}^{2}$ & $L / D$ & 1 & 7.656 & 2.5 & 1.225 & 0.725 & 0.479 & 0.339 \\
\hline Gravity acceleration 1 & $\mathrm{~m} / \mathrm{s}^{2}$ & $L / D$ & 1 & 7.656 & 2.5 & 1.225 & 0.725 & 0.479 & 0.339 \\
\hline Gravity acceleration 2 & $\mathrm{~m} / \mathrm{s}^{2}$ & 1 & 1 & 1 & 1 & 1 & 1 & 1 & 1 \\
\hline
\end{tabular}

$\left|a_{\mathrm{e}}-C\left(v_{\mathrm{e}}-v_{\mathrm{s}}\right) / m\right| \leq \mu g\left(\Delta t_{i}=t_{i}-t_{i-1}\right.$ and $t_{i}$ is the $i$ th time of ground motion), the cases (1) and (2)(2) would convert to case (2) (1).

The case (2)(1) was defined as the nonrolling state, and the structural instantaneous motion was the same as the ground. Hence, it could be easily obtained. When $\left|a_{\mathrm{e}}\right|>\mu g$, the case (2)(1) would convert to the cases (1) and (2)(2).

The calculated seismic responses of scaled models were returned to that of the prototype model with errors. These errors were evaluated by the ratios of the returned responses to the directly calculated responses of the prototype model. These ratios were defined as the returned ratio (RR) by equation (1), which was used to analyze the scaling friction effects in the numerically simulated shaking table tests:

returned ratio $(R R)=\frac{\text { responses returned from scaled model }}{\text { responses calculated for prototype model }}$.

A large number of structural acceleration response ratios (ARR), relative velocity response ratios (RVRR), relative displacement response ratios (relative DRR), and residual displacement response ratios (residual DRR) were obtained based on equation (1). Only common results were listed and discussed in the following sections.

\section{Results with Scaled Gravity and without Scaled Density}

3.1. Cases with Absolutely Uniform Friction Distribution. This section analyzes the returned ratios, defined by equation (1), for the most idealized uniform friction case 1 in Figure 2. The scaled model adopts the density of the prototype structure and the theoretically scaled gravity acceleration of the row "gravity acceleration 1," in Table 1. There is no gravity distortion in the scaled model.

When the uniform friction distribution $(R=0)$ is combined with the viscous damper having $C=100 \mathrm{kN} \cdot \mathrm{s} / \mathrm{m}$, the ratios RR in Figure 4 are close to 1.0. The largest errors exist for some structural residual displacement ratios (residual DRR); however, these are acceptable since they are less than $20 \%$. Because it is difficult to predict the earthquake load, the errors of earthquake load are much larger than other general loads acted on the civil engineering. Therefore, $20 \%$ is set as the limitation of allowable error for the seismic engineering in this paper. 


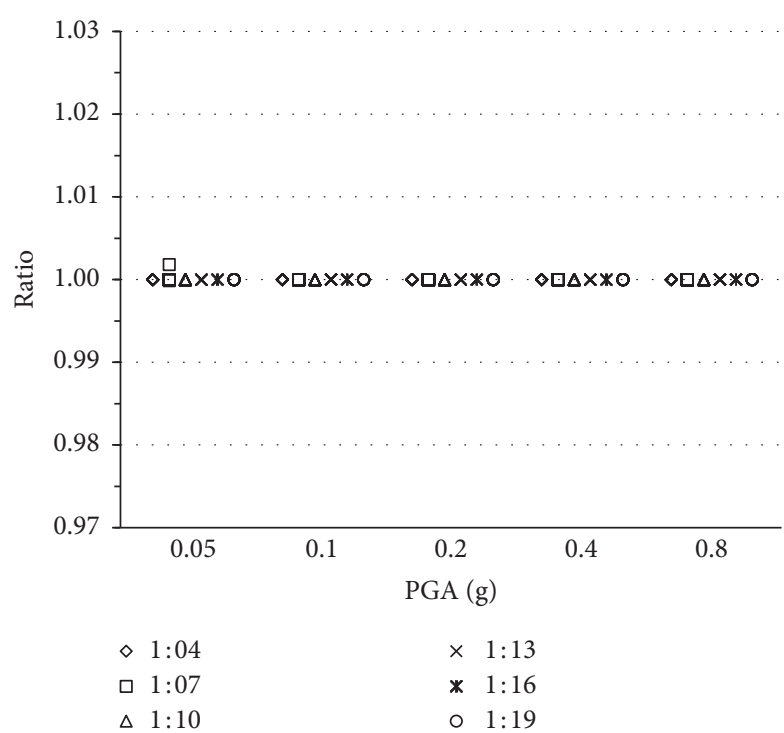

(a)

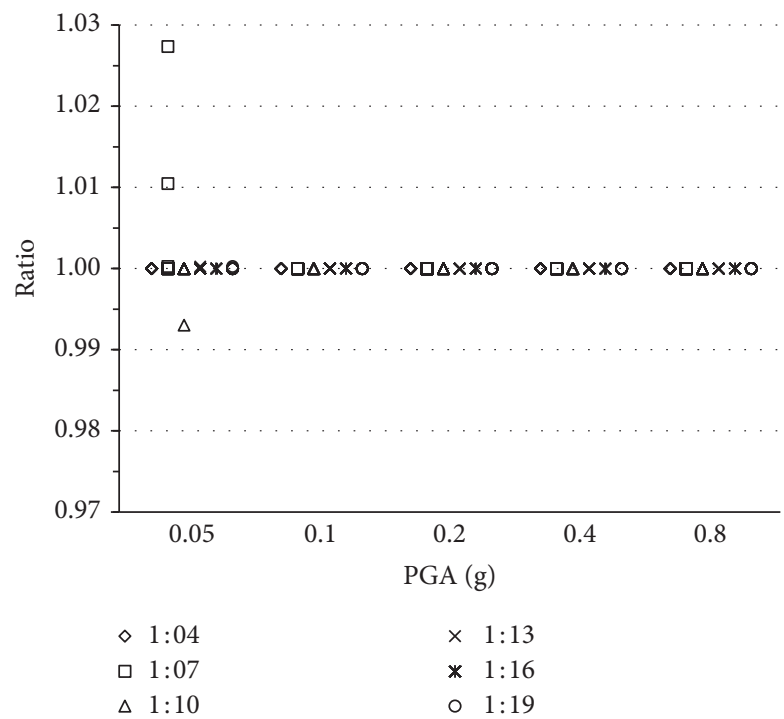

(c)

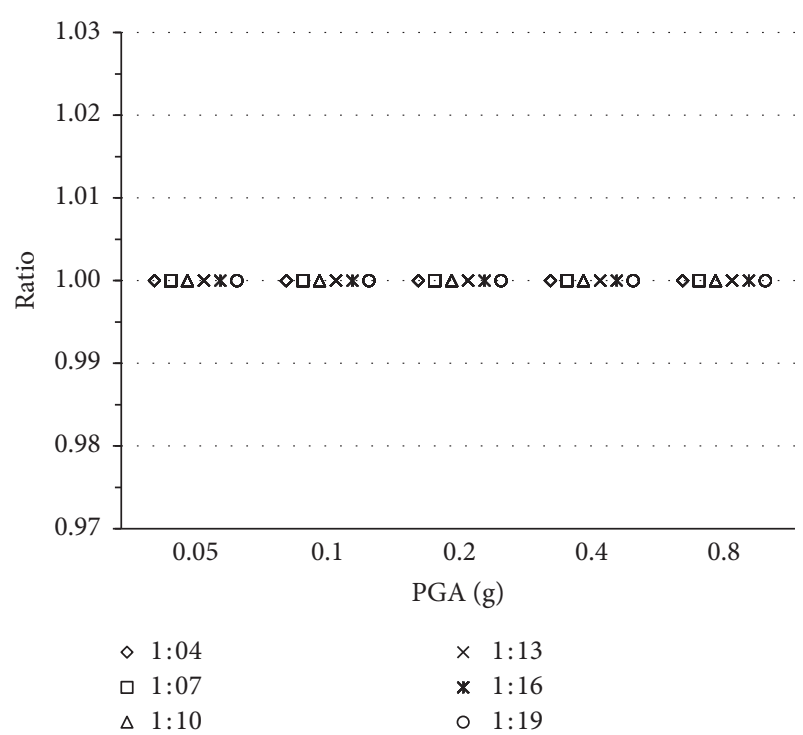

(b)

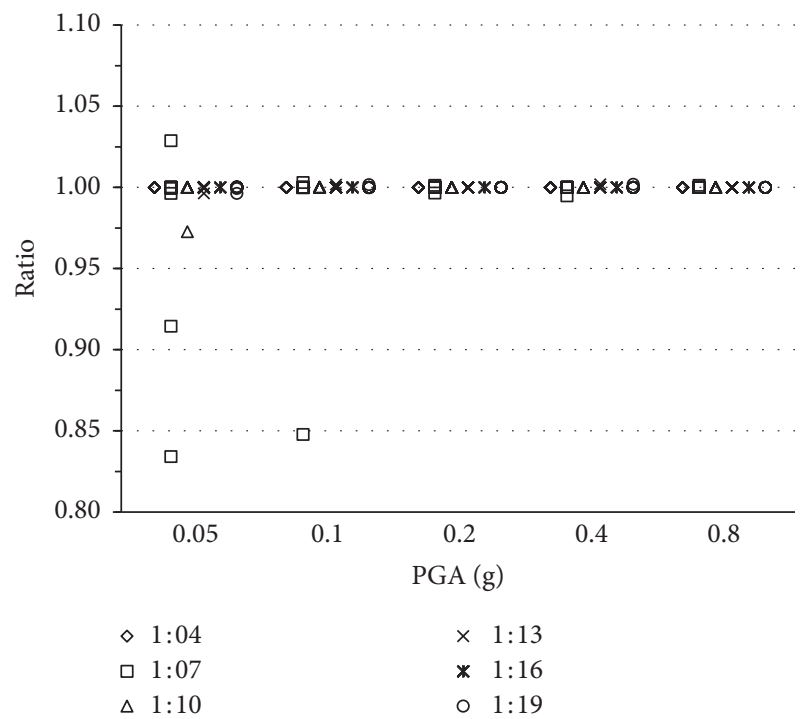

(d)

FIgURE 4: RR (defined in equation (1)) for case 1 in Figure 2, with $R=0$ and $C=100 \mathrm{kN} \cdot \mathrm{s} / \mathrm{m}$, with scaled gravity and without scaled density. (a) Structural acceleration. (b) Structural relative velocity. (c) Structural relative displacement. (d) Structural residual displacement.

The unlisted ratios, RR, of other uniform friction distribution cases, combined with different damping constants $C$, almost have the same rule as the case above. The different damping constants $C$ do not have the obvious influence on the ratios RR for the most idealized uniform friction case 1 in Figure 2. Namely, the response values returned from the scaled model can represent the responses of the prototype model.

Although friction is nonlinear, the scale theory is still applicable for the uniform friction distribution cases combined with the viscous damper.

3.2. Cases with Friction Variation. The above uniform friction distribution cases are not true in practice. The real friction distribution has the friction coefficient changing in space, such as in cases 2 and 3 in Figure 2.
The returned ratios RR of the case, formed by combining the uneven friction distribution of case 3 in Figure 2 with the damping constant $C=100 \mathrm{kN} \cdot \mathrm{s} / \mathrm{m}$, are shown in Figure 5 . Being of the same value as the above section, the density is not scaled for the scaled model while the gravity acceleration is fully scaled. However, there is a large distribution range for the returned ratios $R R$, which is obviously different from that in the above section. More precisely, the distribution range of ratios $R R$, for the structural acceleration, relative velocity, and relative and residual displacements, becomes successively wider. It implies that the responses returned from the scaled model cannot represent the responses of prototype model when there is a considerable variation of friction in space.

These returned ratios RR, including that of cases 2 and 3 in Figure 2 combined with the damping constants $C=100$ 

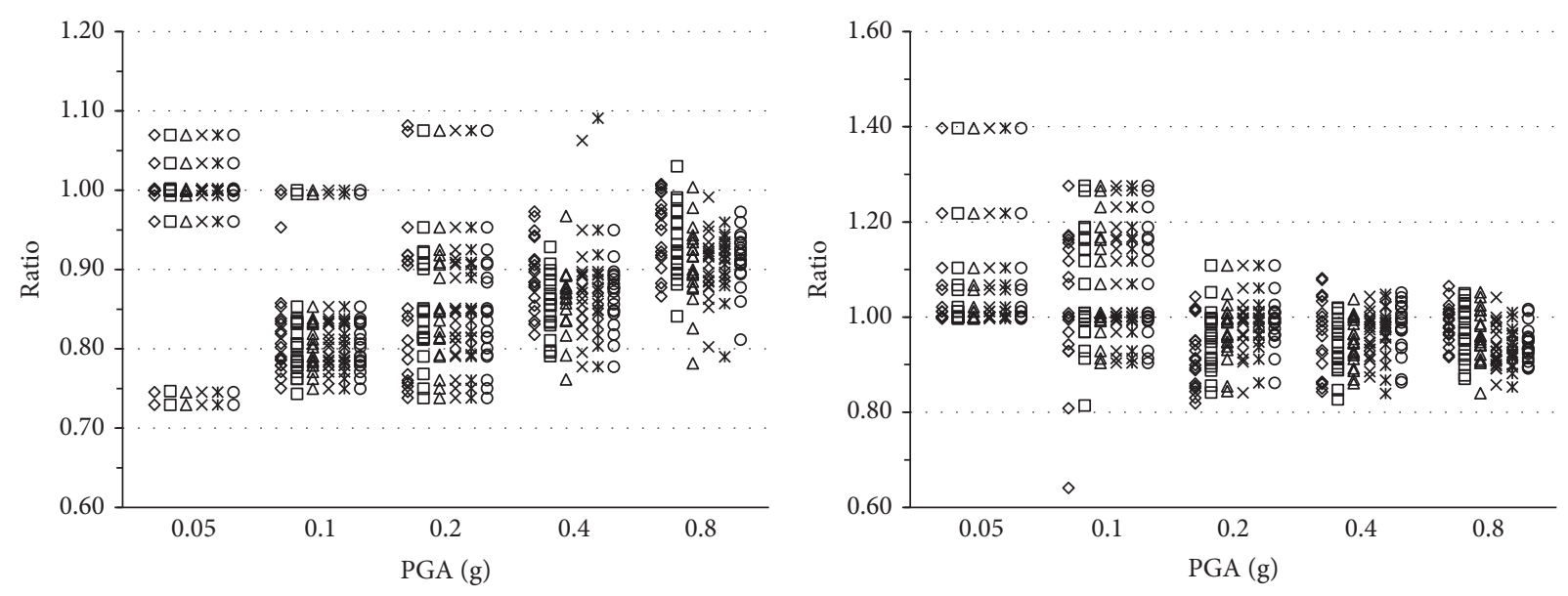
$\diamond 1: 04$
口 1:07
$\Delta 1: 10$
$\times \quad 1: 13$
* $1: 16$
○ $1: 19$

(a)

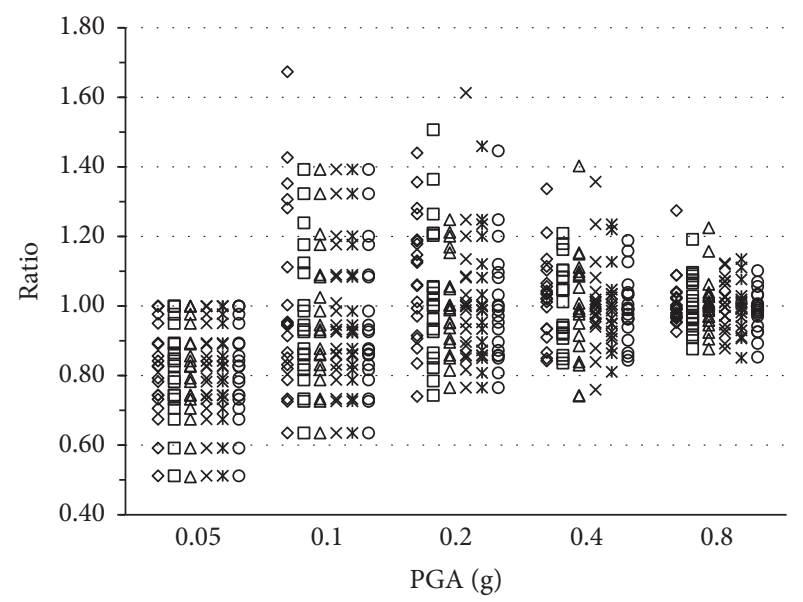
$\diamond 1: 04$
口 1:07
$\Delta 1: 10$

$\diamond 1: 04$

1:07

$\Delta 1: 10$

$\times \quad 1.16$

(b)

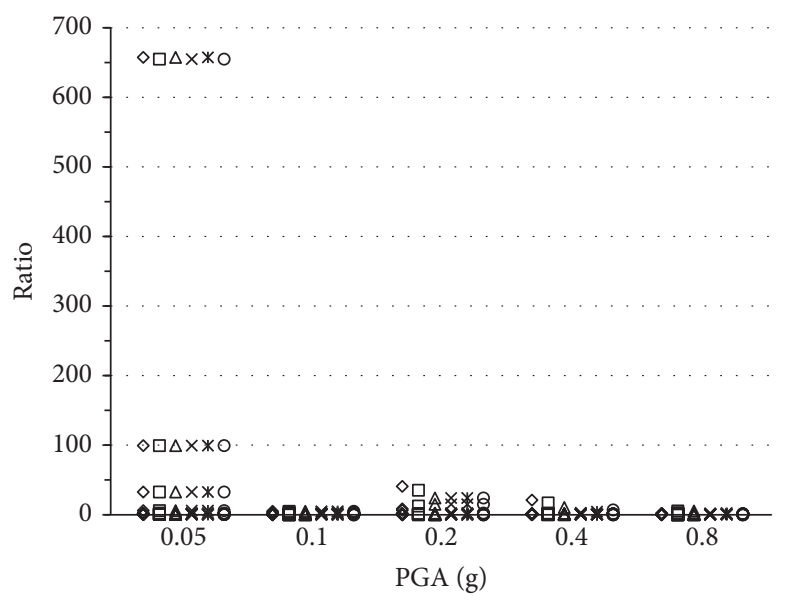
$\diamond 1: 04$
1:07
$\Delta 1: 10$

$\times 1: 13$

* $1: 16$

○ $1: 19$

(d)

FIgUre 5: Continued. 


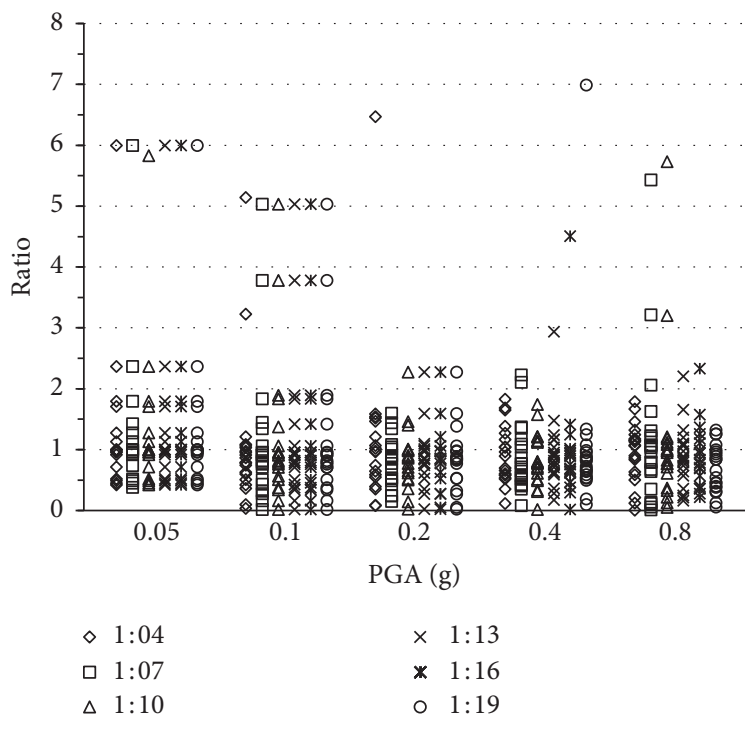

(e)

Figure 5: RR (defined in equation (1)) for case 3 in Figure 2, with $R=0$ and $C=100 \mathrm{kN} \cdot \mathrm{s} / \mathrm{m}$, with scaled gravity, without scaled density, and without scaled friction. (a) Structural acceleration. (b) Structural relative velocity. (c) Structural relative displacement. (d) Structural residual displacement (all points). (e) Structural residual displacement (main points).

and $200 \mathrm{kN} \cdot \mathrm{s} / \mathrm{m}$, are summarized in Table 3 . The distribution range of these ratios $\mathrm{RR}$ becomes wider with an increase of the friction variation coefficient; however, it becomes less with an increase of the damping constant $C$. The latter rule is more obvious for case 3, with a more considerable friction variation in space. The reason is that the friction and the viscous damping have the same function of energy dissipation [33], and the increase in the damping constant reduces the influence of friction variation on the energy dissipation and seismic responses.

As to decrease the above returned errors, more work needs to be done for scaling the friction variation in space. As one position corresponds to one specific friction coefficient, every friction position is moved when scaling the contact surface. Following this additional work, the returned ratios RR related to the cases in Figure 5 are shown in Figure 6.

The returned ratios RR in Figure 6 are much closer to 1.0 than that in Figure 5, except some special points of structural residual displacement. The reason for these special points is that the denominator of equation (1) is too small for some structural residual displacements, and a little absolute difference between the numerator and the denominator leads to a larger returned ratio RR. Most of the returned ratios RR in Figure 6 imply that the response values returned from the scaled model can represent the responses of the prototype model with the friction variation in space. However, it needs the additional work, as already mentioned.

It may be noted that this friction scaling process has been carried out for concave friction distribution cases in Figure 1, and the scaling parameters are listed in the row "friction increment ratio", in Table 1. The corresponding returned ratios $R R$, defined by equation (1), are almost close to 1.0 except for some special points for the structural residual displacement, with much lower absolute values.
These corresponding figures, being similar with Figure 6, are not listed here due to space limitations.

\section{Results with Scaled Gravity and with Scaled Density}

The above section adopts the scaling factors mentioned in Table 1; however, this section uses the scaling factors listed in Table 2. The density of the scaled model is the same as the prototype model in Table 1 but has been scaled in Table 2 . This section rigorously scales the gravity acceleration in the same manner as has been done in the above section.

The calculation cases and the returned ratios RR distribution are almost the same as that in the above section. This section does not list and discuss these similar results.

\section{Results without Scaled Gravity and without Scaled Density}

5.1. Cases without Friction Scale. This section analyzes the returned ratios, defined by equation (1), for the most idealized uniform friction case 1 in Figure 2. The scaled model adopts the density of the prototype structure and the unscaled gravity acceleration of the row "gravity acceleration 2," in Table 1. The scaled model is the gravity distortion model.

Being similar to the section prior to the previous section, a viscous damper-Coulomb friction system is obtained by combining the uniform friction distribution $(R=0)$ with $C=100 \mathrm{kN} \cdot \mathrm{s} / \mathrm{m}$. Its prototype and scaled models are numerically analyzed. The returned ratios, calculated from the numerical results according to equation (1), are shown in Figure 7.

In Figure 7(a), the returned ratios ARR are underestimated. The reason is that the unscaled gravity acceleration $g$ of the scaled model is underestimated, and the 
TABLE 3: Ratios of results returned from scaled models to that of the full-scale model.

\begin{tabular}{|c|c|c|c|c|c|c|c|}
\hline \multirow{2}{*}{$\begin{array}{l}\text { Damping constant } \\
(\mathrm{kN} \cdot \mathrm{s} / \mathrm{m})\end{array}$} & \multicolumn{3}{|c|}{ Friction coefficient } & \multicolumn{4}{|c|}{$\begin{array}{l}\text { Ratios of results returned from scaled models to that of full-scale } \\
\text { model (RR defined in equation (1)) }\end{array}$} \\
\hline & $\begin{array}{l}\text { Average } \\
\text { value }\end{array}$ & Cases & $\begin{array}{l}\text { Variation } \\
\text { coefficient }\end{array}$ & Acceleration & $\begin{array}{l}\text { Relative } \\
\text { velocity }\end{array}$ & $\begin{array}{c}\text { Relative } \\
\text { displacement }\end{array}$ & $\begin{array}{c}\text { Residual } \\
\text { displacement }\end{array}$ \\
\hline \multirow{2}{*}{100} & \multirow{2}{*}{0.005} & Case 2 & 0.163 & $0.82 \sim 1.03$ & $0.88 \sim 1.07$ & $0.71 \sim 1.22$ & $0 \sim 15$ \\
\hline & & Case 3 & 0.471 & $0.71 \sim 1.10$ & $0.62 \sim 1.40$ & $0.49 \sim 1.67$ & $0 \sim 650$ \\
\hline \multirow{2}{*}{200} & \multirow{2}{*}{0.005} & Case 2 & 0.163 & $0.83 \sim 1.18$ & $0.91 \sim 1.07$ & $0.72 \sim 1.42$ & $0 \sim 11$ \\
\hline & & Case 3 & 0.471 & $0.72 \sim 1.12$ & $0.72 \sim 1.22$ & $0.54 \sim 1.49$ & $0 \sim 21$ \\
\hline
\end{tabular}
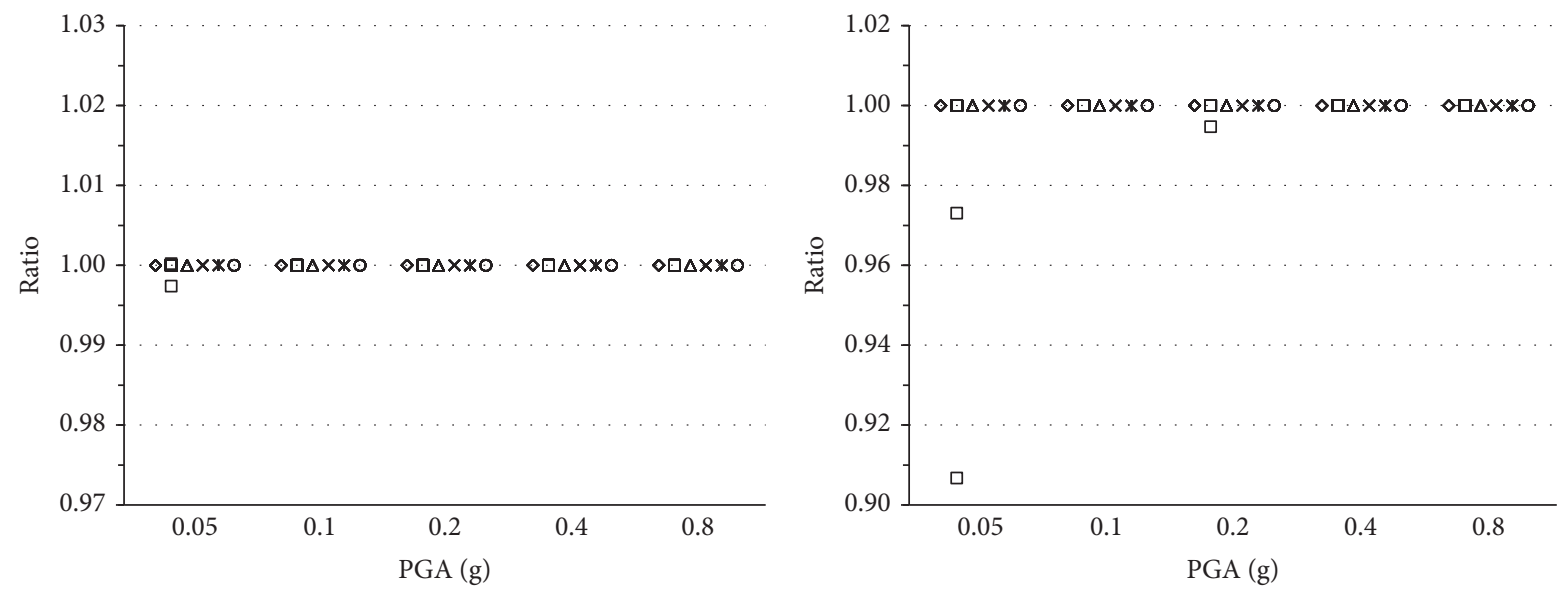
$\diamond 1: 04$
$\times \quad 1: 13$
$1: 07$
$\times \quad 1: 16$
$\Delta 1: 10$
○ $1: 19$

$\begin{array}{ll}\diamond 1: 04 & \times 1: 13 \\ \text { } 1: 07 & \times 1: 16 \\ \triangle 1: 10 & \circ 1: 19\end{array}$

(a)

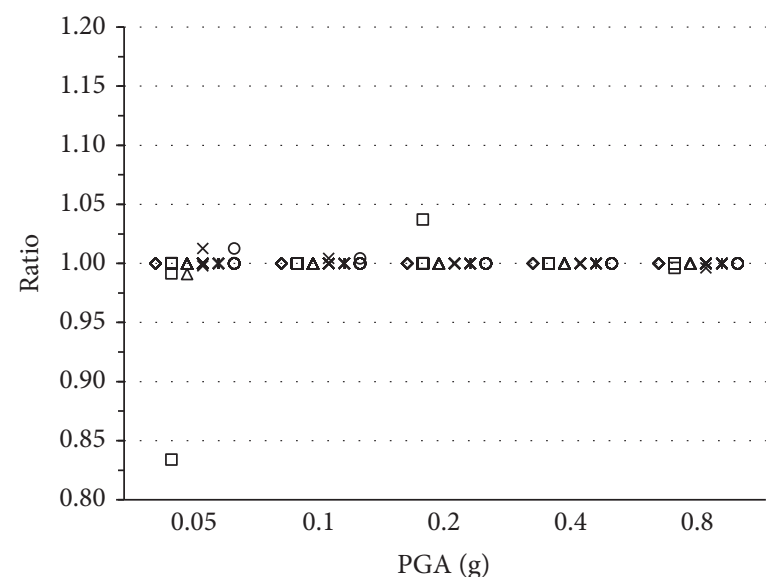

(b)

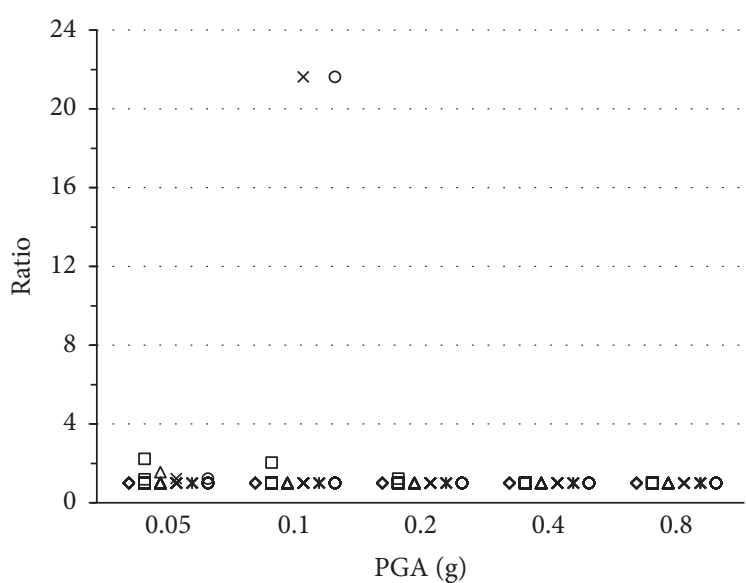
$\diamond 1: 04$
$\times 1: 13$
$\diamond 1: 04$
$\times \quad 1: 13$
1:07
$\times \quad 1: 16$
1:07
$\times \quad 1: 16$
$\Delta 1: 10$
○ $1: 19$
$\Delta 1: 10$
○ $1: 19$

(c)

Figure 6: Continued.

(d) 


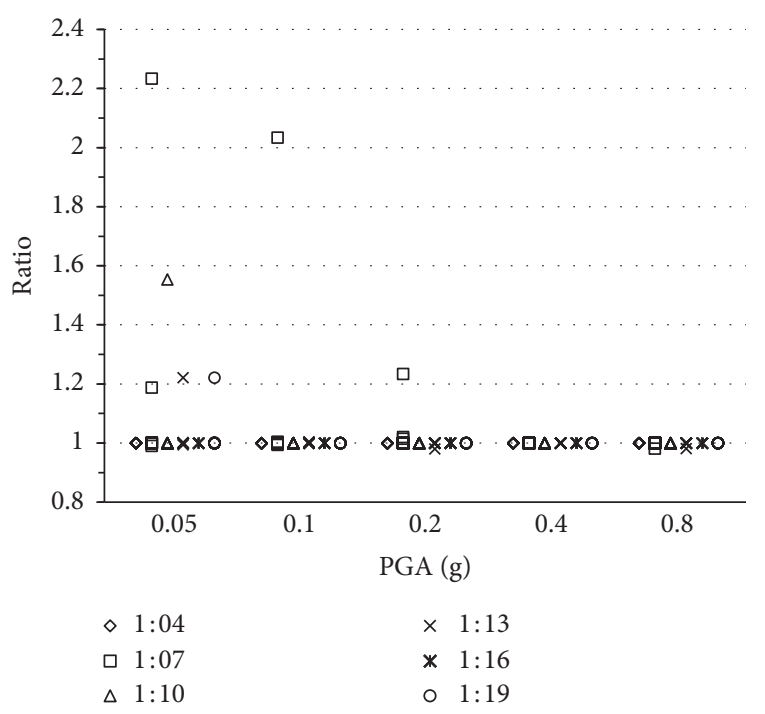

(e)

FIgURE 6: RR (defined in equation (1)) for case 3 in Figure 2, with $R=0$ and $C=100 \mathrm{kN} \cdot \mathrm{s} / \mathrm{m}$, with scaled gravity, without scaled density, and with scaled friction. (a) Structural acceleration. (b) Structural relative velocity. (c) Structural relative displacement. (d) Structural residual displacement (all points). (e) Structural residual displacement (main points).

underestimated ratio is just the model scale when compared with the theoretical value. This underestimated gravity acceleration $g$ reduces the acceleration $\mu g+C\left(v_{\mathrm{e}}-v_{\mathrm{s}}\right) / m$ in the scaled model.

In Figure 7(a), an increase in PGA enlarges the relative velocity $\left(v_{\mathrm{e}}-v_{\mathrm{s}}\right)$ and the term $C\left(v_{\mathrm{e}}-v_{\mathrm{s}}\right) / m$. Therefore, it reduces the underestimated gravity effects on the acceleration $\mu g+C\left(v_{\mathrm{e}}-v_{\mathrm{s}}\right) / m$ of the scaled model. It further increases the returned ratios ARR to trend to 1.0.

This trend further increases the underestimated returned ratios RVRR in Figure 7(b) when PGA increases.

Based on the same reasons above, there is a much larger distribution range for the returned ratios "relative DRR" and "residual DRR," in Figures 7(c) and 7(d), respectively. When PGA increases, the returned ratios "relative DRR" in Figure $7(\mathrm{c})$ trend to 1.0; however, the returned ratios "residual DRR" in Figure 7(d) change irregularly.

Finally, other friction distribution cases including the concave pattern, combined with different damping constants $C$, are numerically analyzed. Too many values and similar phenomena are obtained but have not been listed for the returned ratios.

To summarize, the gravity distortion leads to seismic response errors in scaled models. However, these errors can be reduced by increasing the term $C\left(v_{\mathrm{e}}-v_{\mathrm{s}}\right) / m$ or PGA and damping constant.

5.2. Cases with Friction Scale. The structural gravity could not be scaled on the common shaking tables [34]. Although the external bars were put forward to equivalently scale the structural gravity by adding a prestress force, the force was found to change during a dynamic test [35]. The new method provides a solution to the problem.

In the above gravity distortion model, the gravity acceleration $g$ is underestimated while the friction coefficient $\mu$ can be increased to keep the whole term $\mu \mathrm{g}$ reasonably scaled. Subsequently, the structural acceleration $\mu g+C\left(v_{\mathrm{e}}-v_{\mathrm{s}}\right) / m$ and other responses are rigorously calculated for the scaled models. The calculated but not listed results show that the returned ratios $R R$, defined by equation (1), are close to 1.0.

\section{Results without Scaled Gravity and with Scaled Density}

6.1. Cases without Friction Scale. This section analyzes the returned ratios, defined by equation (1), for the most optimal uniform friction case 1 in Figure 2. The scaled model adopts the scaled density and the unscaled gravity acceleration of the row "gravity acceleration 2", in Table 2. The scaled model is the gravity distortion model similar to the previous section.

The scaled models of the prototype model with a damping constant $C=100 \mathrm{kN} \cdot \mathrm{s} / \mathrm{m}$ are numerically analyzed. The returned ratios $\mathrm{RR}$, calculated from the numerical results according to equation (1), are shown in Figure 8.

Figure $8(\mathrm{a})$ indicates that the structural acceleration responses of scaled models are underestimated or overestimated. The reason is that the unscaled gravity acceleration $g$ of scaled models is underestimated or overestimated, and this misestimated gravity acceleration $g$ further leads to errors in the acceleration $\mu g+C\left(v_{\mathrm{e}}-v_{\mathrm{s}}\right) / m$ of scaled models.

In Figure 8(a), an increase in PGA enlarges the relative velocity $\left(v_{\mathrm{e}}-v_{\mathrm{s}}\right)$ and the term $C\left(v_{\mathrm{e}}-v_{\mathrm{s}}\right) / m$. Therefore, it reduces the misestimated gravity effects on the acceleration $\mu g+C\left(v_{\mathrm{e}}-v_{\mathrm{s}}\right) / m$ of scaled models. It further makes the returned ratios ARR come closer to 1.0.

The returned ratios RVRR and "relative DRR" in Figures $8(\mathrm{~b})$ and $8(\mathrm{c})$ are closer to 1.0 when PGA increases. It is similar to the previous section. However, the returned ratio "residual DRR" in Figure 8(d) changes irregularly. 

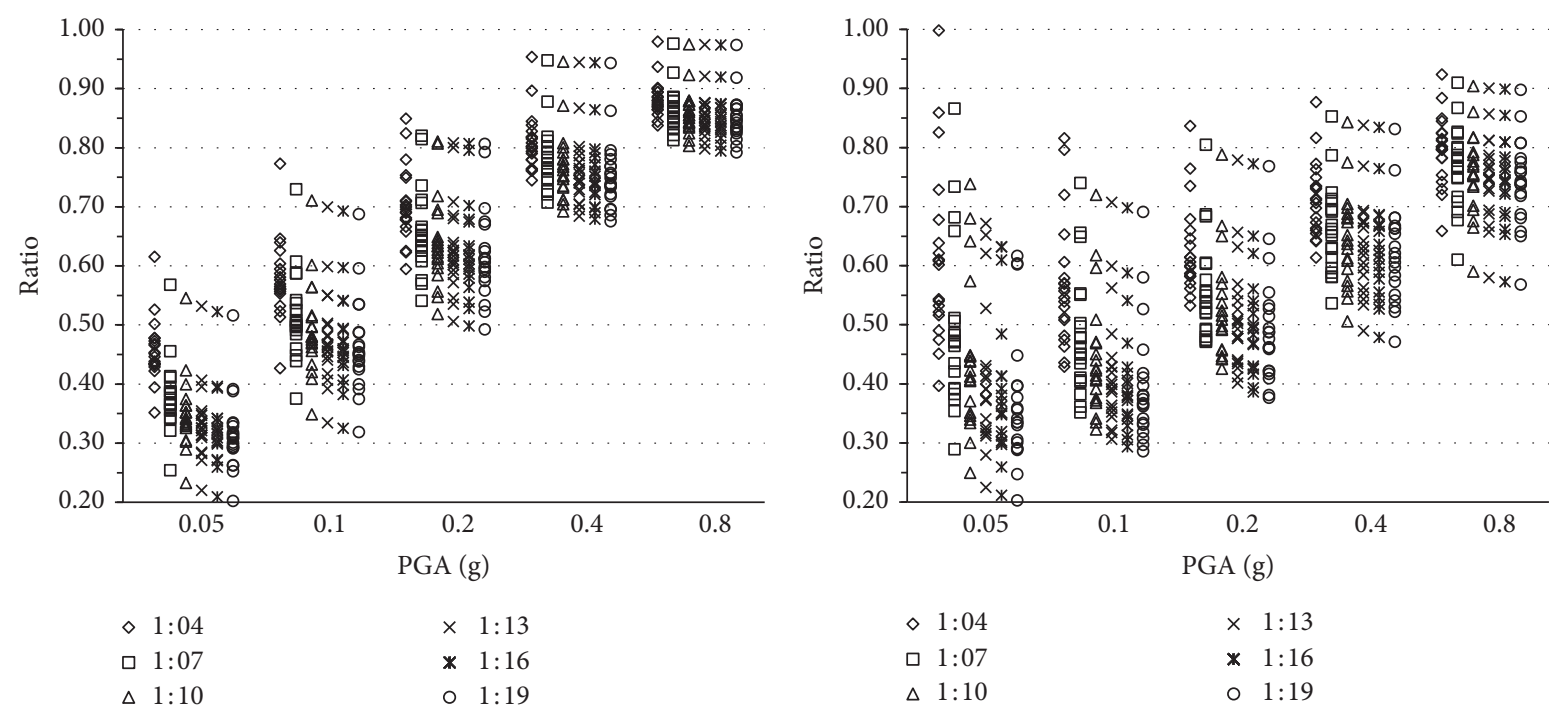

(a)

(b)
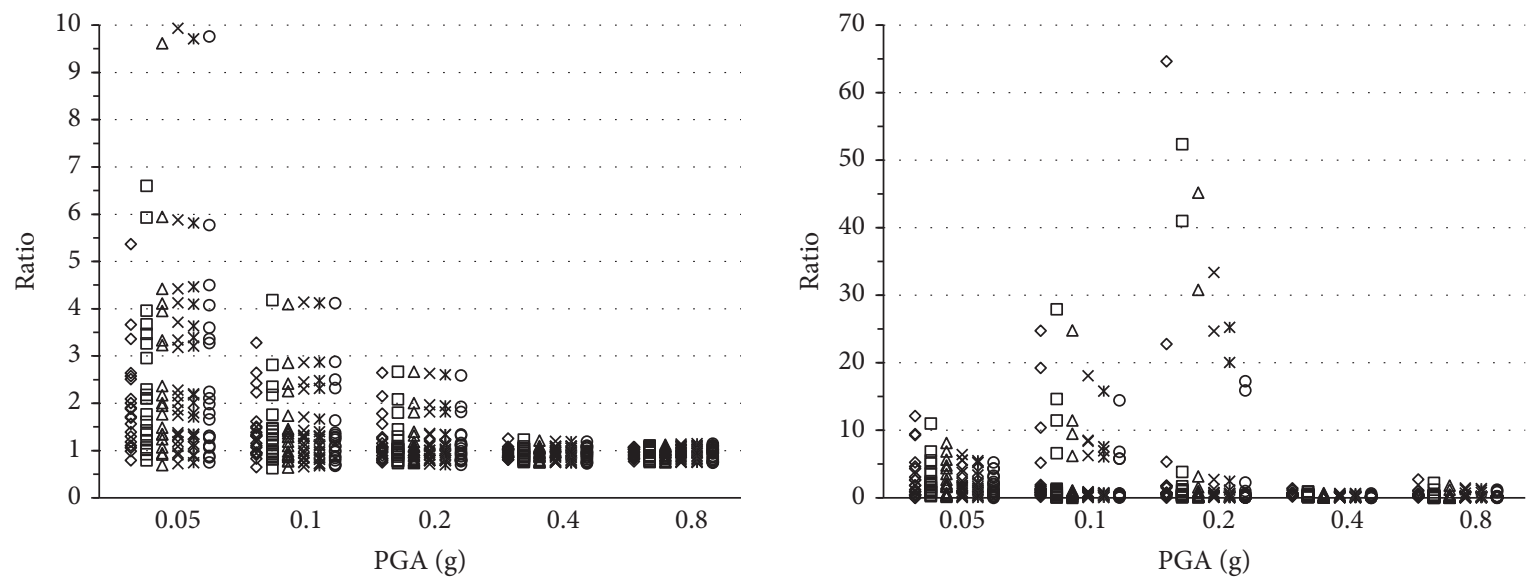
$\diamond 1: 04$
$\times \quad 1: 13$
1:07
* $1: 16$
$\Delta 1: 10$
○ $1: 19$

$\diamond 1: 04$

$\times \quad 1: 13$

1:07

* $1: 16$

$\Delta 1: 10$

○ $1: 19$

(c)

(d)

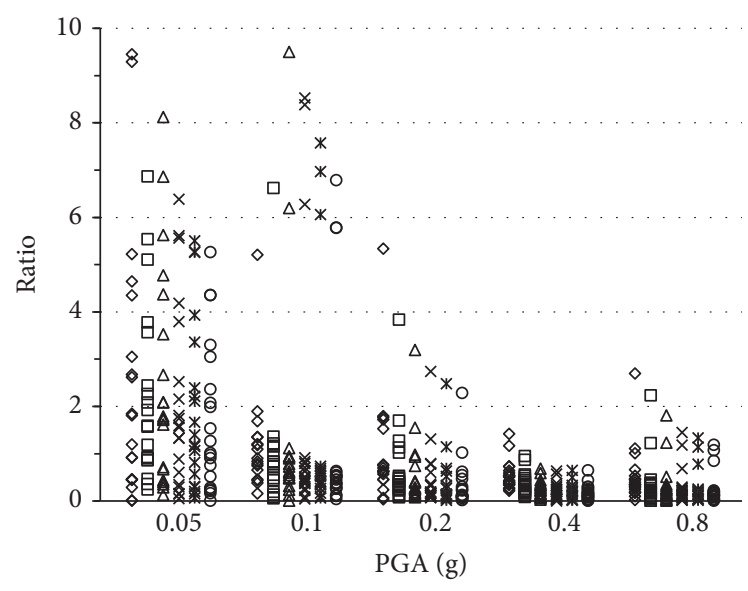
$\diamond 1: 04$
$\times 1: 13$
1:07
* $1: 16$
$\Delta 1: 10$
○ $1: 19$

(e)

FIgURE 7: RR (defined in equation (1)) for case 1 in Figure 2, with $R=0$ and $C=100 \mathrm{kN} \cdot \mathrm{s} / \mathrm{m}$, without scaled gravity, without scaled density, and without scaled friction. (a) Structural acceleration. (b) Structural relative velocity. (c) Structural relative displacement. (d) Structural residual displacement (all points). (e) Structural residual displacement (main points). 


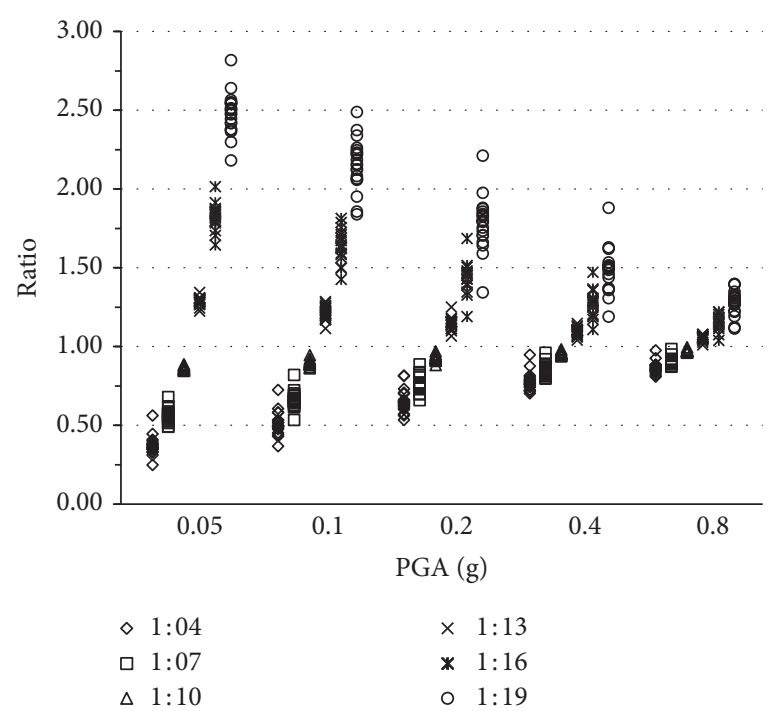

(a)

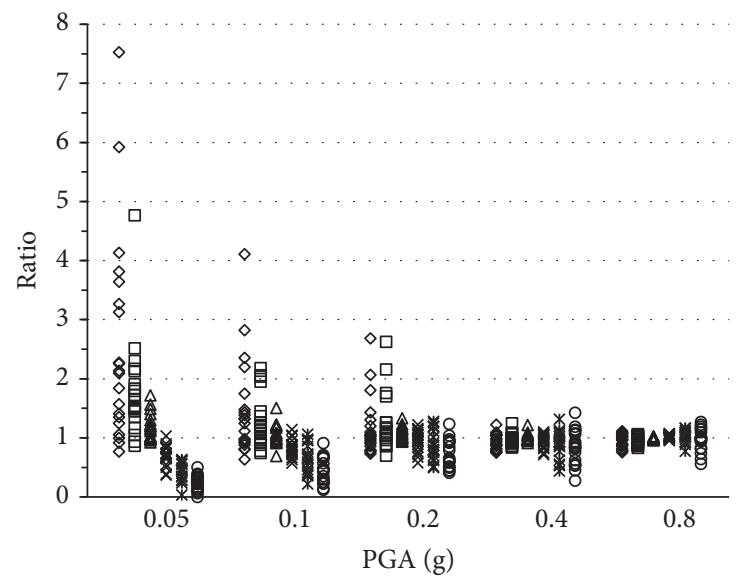

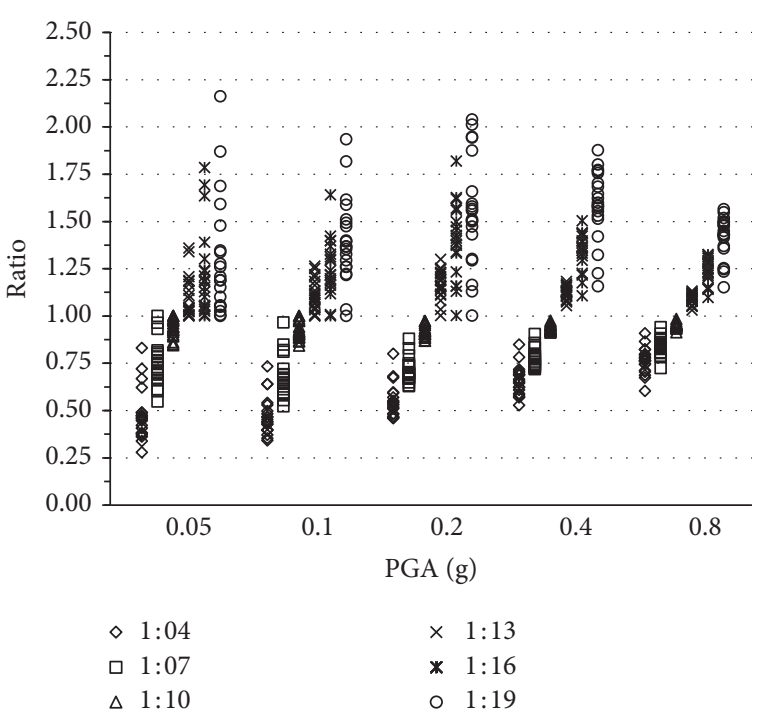

(b)

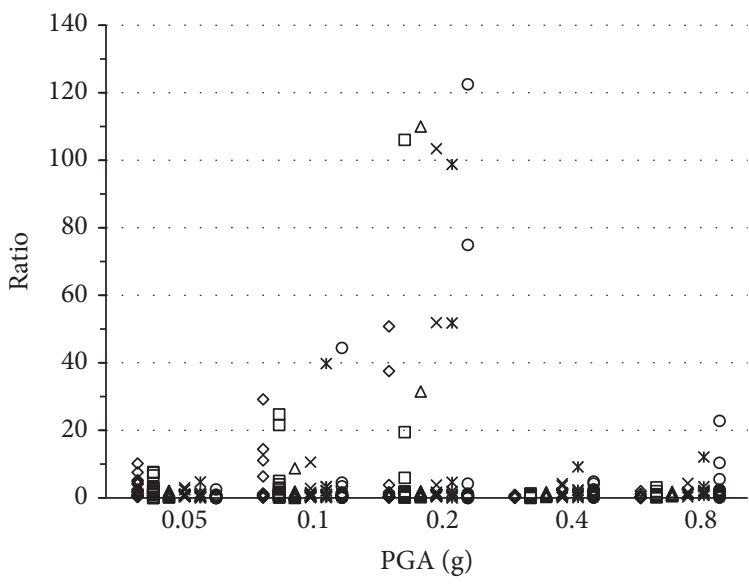
$\diamond 1: 04$
$\times \quad 1: 13$
口 1:07
* $1: 16$
$\triangle 1: 10$
- $1: 19$

(d)

(c)

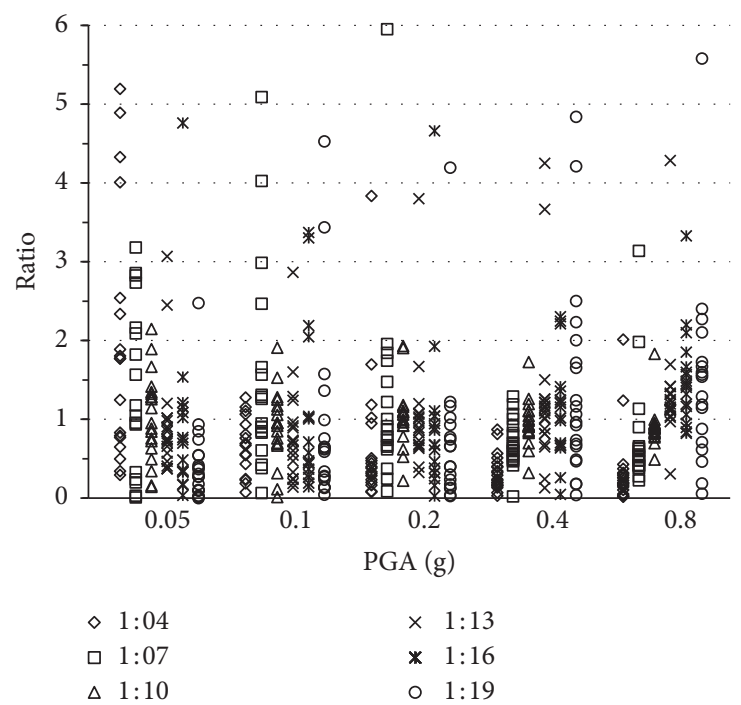

(e)

Figure 8: RR (defined in equation (1)) for case 1 in Figure 2, with $R=0$ and $C=100 \mathrm{kN} \cdot \mathrm{s} / \mathrm{m}$, without scaled gravity, with scaled density, and without scaled friction. (a) Structural acceleration. (b) Structural relative velocity. (c) Structural relative displacement. (d) Structural residual displacement (all points). (e) Structural residual displacement (main points). 
Figure 8 shows a special case that the returned ratios ARR, RVRR, "relative DRR," and "residual DRR" are always close to 1.0 for the model scale $1: 10$. The reason is that the theoretical acceleration scale 1.225 is close to 1.0 in Table 2, and the gravity distortion effect is weakened for the model scale $1: 10$. It implies that the density, size, and other parameter scales can be adjusted to weaken or even avoid the gravity distortion effect.

Finally, other friction distribution cases including the concave pattern, combined with different damping constants $C$, are numerically analyzed. Being similar to the previous section, the gravity distortion leads to the seismic response errors in the scaled models. However, these errors are reduced by increasing the second term $C\left(v_{\mathrm{e}}-v_{\mathrm{s}}\right) / m$ in the structural acceleration $\mu g+C\left(v_{\mathrm{e}}-v_{\mathrm{s}}\right) / m$, i.e., increasing the damping constant $C$ or PGA.

6.2. Cases with Friction Scale. The first term $\mu \mathrm{g}$ of structural acceleration $\mu g+C\left(v_{\mathrm{e}}-v_{\mathrm{s}}\right) / m$ is rigorously scaled by appropriately adjusting the friction coefficient $\mu$ to offset the misestimated gravity acceleration $g$. The too many unlisted results show that the returned ratios RR for any calculation cases are always close to 1.0 .

\section{Conclusions}

The rolling action could isolate and dissipate the seismic energy during earthquakes. As to further reduce the structural relative displacement, a viscous damper was added to the Coulomb friction system to dissipate the seismic energy more efficiently around the center of contact surface. The viscous damper-Coulomb friction system was scaled in a numerically simulated shaking table test. The seismic responses of scaled models and prototype model were compared with each other. The scaling friction effects are summarized as follows:

(1) The gravity distortion leads to seismic response errors in scaled models. The reason is that the gravity distortion leads to an adverse friction force and other responses. This paper gives two solutions to the problem: (1) the friction coefficient is changed to adjust the friction force; (2) the density, size, and other parameter scales are adjusted to make the gravity acceleration scale to be just 1.0.

(2) The friction variation in space also leads to seismic response errors in scaled models. The reason is that the contact surface is scaled while the friction distribution is not scaled. This paper gives one solution to the problem: the positions of specific friction coefficients are moved with the scaled length of contact surface.

(3) The influence degrees of the abovementioned gravity distortion and spatial friction variation are weakened by increasing PGA or viscous damping constant. It is necessary to explain that all of the above solutions are only efficient for Coulomb friction. The solution, for when the time-variant friction is scaled, needs further research.

\section{Data Availability}

The data used to support the findings of this study are included within the article. The data include the structural parameters, ground motion inputs, calculation methods, and calculation results.

\section{Conflicts of Interest}

The authors declare that they have no conflicts of interest.

\section{Acknowledgments}

This research was jointly supported by the National Natural Science Foundations of China under grant nos. 51778635 and 51778630 , the Natural Science Foundations of Hunan Province under grant no. 2019JJ40386, the Research Program on Displacement Limitation Technology of Half-Through Railway Arch Bridge under grant no. science2018-81, the Science and Technology Project of Sichuan Province under grant no. 2019YFG0048, the Xuzhou Science and Technology Project under grant no. 201718, and the Project of Jiangsu Housing and Urban-Rural Development Department under grant no. 2017ZD012. The above support is greatly appreciated.

\section{References}

[1] R. P. Nanda, P. Agarwal, and M. Shrikhande, "Base isolation system suitable for masonry buildings," Asian Journal of Civil Engineering (Building and Housing), vol. 13, no. 2, pp. 195202, 2012.

[2] K. Kurita, S. Aoki, Y. Nakanishi, K. Tominaga, and M. Kanazawa, "Fundamental characteristics of reduction system for seismic response using friction force," Journal of Civil Engineering and Architecture, vol. 5, no. 11, pp. 10421047, 2011.

[3] M. Ismail and J. R. Casas, "Novel isolation device for protection of cable-stayed bridges against near-fault earthquakes," Journal of Bridge Engineering, vol. 19, no. 8, Article ID A4013002, 2014.

[4] M. Ismail, J. Rodellar, and F. Pozo, "An isolation device for near-fault ground motions," Structural Control and Health Monitoring, vol. 21, no. 3, pp. 249-268, 2014.

[5] M. Ismail, "An isolation system for limited seismic gaps in near-fault zones," Earthquake Engineering \& Structural Dynamics, vol. 44, no. 7, pp. 1115-1137, 2015.

[6] S.-J. Wang, J.-S. Hwang, K.-C. Chang et al., "Sloped multiroller isolation devices for seismic protection of equipment and facilities," Earthquake Engineering \& Structural Dynamics, vol. 43, no. 10, pp. 1443-1461, 2014.

[7] L. Guerreiro, J. Azevedo, and A. H. Muhr, "Seismic tests and numerical modeling of a rolling-ball isolation system," Journal of Earthquake Engineering, vol. 11, no. 1, pp. 49-66, 2007.

[8] R. S. Jangid and Y. B. Londhe, "Effectiveness of elliptical rolling rods for base isolation," Journal of Structural Engineering, vol. 124, no. 4, pp. 469-472, 1998.

[9] R. S. Jangid, "Stochastic seismic response of structures isolated by rolling rods," Engineering Structures, vol. 22, no. 8, pp. 937-946, 2000.

[10] S. Cui, Integrated Design Methodology for Isolated Floor Systems in Single-Degree-of-Freedom Structural Fuse Systems, 
Ph.D. dissertation, State University of New York, Buffalo, NY, USA, 2012.

[11] T. Peng, J. Li, Y. Xu, and L. Fan, "Study on the seismic performance of a double spherical seismic isolation bearing," Earthquake Engineering and Engineering Vibration, vol. 7, no. 4, pp. 439-446, 2008.

[12] F. Mazza, "Lateral-torsional response of base-isolated buildings with curved surface sliding system subjected to near-fault earthquakes," Mechanical Systems and Signal Processing, vol. 92, pp. 64-85, 2017.

[13] E. Abalı and E. Uçkan, "Parametric analysis of liquid storage tanks base isolated by curved surface sliding bearings," Soil Dynamics and Earthquake Engineering, vol. 30, no. 1-2, pp. 21-31, 2010.

[14] P. S. Harvey and H. P. Gavin, "The nonholonomic and chaotic nature of a rolling isolation system," Journal of Sound and Vibration, vol. 332, no. 14, pp. 3535-3551, 2013.

[15] P. S. Harvey and H. P. Gavin, "Double rolling isolation systems: a mathematical model and experimental validation," International Journal of Non-linear Mechanics, vol. 61, no. 5, pp. 80-92, 2014.

[16] P. S. Harvey and H. P. Gavin, "Assessment of a rolling isolation system using reduced order structural models," Engineering Structures, vol. 99, pp. 708-725, 2015.

[17] N. A. Ortiz, C. Magluta, and N. Roitman, "Numerical and experimental studies of a building with roller seismic isolation bearings," Structural Engineering and Mechanics, vol. 54, no. 3, pp. 475-489, 2015.

[18] Y. C. Ou, J. W. Song, and G. C. Lee, "A parametric study of seismic behavior of roller seismic isolation bearings for highway bridges," Earthquake Engineering and Structure Dynamics, vol. 39, no. 5, pp. 541-559, 2010.

[19] G. C. Lee, Y.-C. Ou, T. Niu, J. Song, and Z. Liang, "Characterization of a roller seismic isolation bearing with supplemental energy dissipation for highway bridges," Journal of Structural Engineering, vol. 136, no. 5, pp. 502-510, 2010.

[20] B. Wei, C. B. Li, X. L. Jia, X. H. He, and M. G. Yang, "Effects of shear keys on seismic performance of an isolation system," Smart Structures and Systems, vol. 24, no. 3, pp. 345-360, 2019.

[21] B. Wei, P. Wang, X. He, and L. Jiang, "The impact of the convex friction distribution on the seismic response of a spring-friction isolation system," KSCE Journal of Civil Engineering, vol. 22, no. 4, pp. 1203-1213, 2018.

[22] B. Wei, P. Wang, W. Liu, M. Yang, and L. Jiang, "The impact of the concave distribution of rolling friction coefficient on the seismic isolation performance of a spring-rolling system," International Journal of Non-linear Mechanics, vol. 83, pp. 65-77, 2016.

[23] B. Wei, T. Yang, L. Jiang, and X. He, "Effects of friction-based fixed bearings on the seismic vulnerability of a high-speed railway continuous bridge," Advances in Structural Engineering, vol. 21, no. 5, pp. 643-657, 2018.

[24] Z.-w. Yu and J.-f. Mao, "Probability analysis of train-trackbridge interactions using a random wheel/rail contact model," Engineering Structures, vol. 144, pp. 120-138, 2017.

[25] B. Wei, C. J. Zuo, X. H. He, and Q. Y. Hu, "Earthquake isolation of a spring-damper-friction system with a convex friction distribution," Journal of Testing and Evaluation, vol. 47, no. 2, Article ID 20170275, 2019.

[26] B. Wei, P. Wang, X. H. He, and L. Z. Jiang, "Seismic isolation characteristics of a friction system," Journal of Testing and Evaluation, vol. 46, no. 4, Article ID 20160598, 2018.
[27] I. V. Kalpakidis, M. C. Constantinou, and A. S. Whittaker, "Modeling strength degradation in lead-rubber bearings under earthquake shaking," Earthquake Engineering \& Structural Dynamics, vol. 39, no. 13, pp. 1533-1549, 2010.

[28] I. V. Kalpakidis and M. C. Constantinou, "Principles of scaling and similarity for testing of lead-rubber bearings," Earthquake Engineering \& Structural Dynamics, vol. 39, no. 13, pp. 1551-1568, 2010.

[29] S. Sorace and G. Terenzi, "Seismic protection of frame structures by fluid viscous damped braces," Journal of Structural Engineering, vol. 134, no. 1, pp. 45-55, 2008.

[30] L.-L. Chung, P.-S. Kao, C.-Y. Yang, L.-Y. Wu, and H.-M. Chen, "Optimal frictional coefficient of structural isolation system," Journal of Vibration and Control, vol. 21, no. 3, pp. 525-538, 2015.

[31] S. Sorace and G. Terenzi, "Existing prefab R/C industrial buildings: seismic assessment and supplemental dampingbased retrofit," Soil Dynamics and Earthquake Engineering, vol. 94, pp. 193-203, 2017.

[32] D. Kosntantinidis and N. Makris, "Experimental and analytical studies on the response of freestanding laboratory equipment to earthquake shaking," Earthquake Engineering \& Structural Dynamics, vol. 38, no. 6, pp. 827-848, 2009.

[33] B. Wei, Y. Zhuo, C. Li, and M. Yang, "Parameter optimization of a vertical spring-viscous damper-Coulomb friction system," Shock and Vibration, vol. 2019, Article ID 5764946, 19 pages, 2019.

[34] G. Q. Shao, L. Z. Jiang, and N. Chouw, "Experimental investigations of the seismic performance of bridge piers with rounded rectangular cross-sections," Earthquakes and Structures, vol. 7, no. 4, pp. 463-484, 2014.

[35] G. L. Chen and L. J. Si, "Discussion on masonry structure model mechanical property test," Applied Mechanics and Materials, vol. 238, pp. 659-662, 2012.

[36] B. Wei, T. Yang, L. Jiang, and X. He, "Effects of uncertain characteristic periods of ground motions on seismic vulnerabilities of a continuous track-bridge system of high-speed railway," Bulletin of Earthquake Engineering, vol. 16, no. 9, pp. 3739-3769, 2018.

[37] Y. Xia, P. Wang, and L. M. Sun, "Neutral axis position based health monitoring and condition assessment techniques for concrete box girder bridges," International Journal of Structural Stability and Dynamics, vol. 19, no. 1, Article ID 1940015, 2019. 


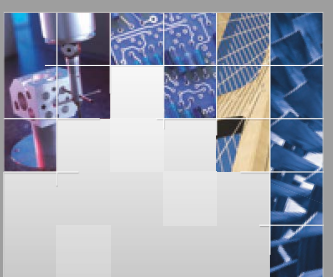

\section{Enfincering}
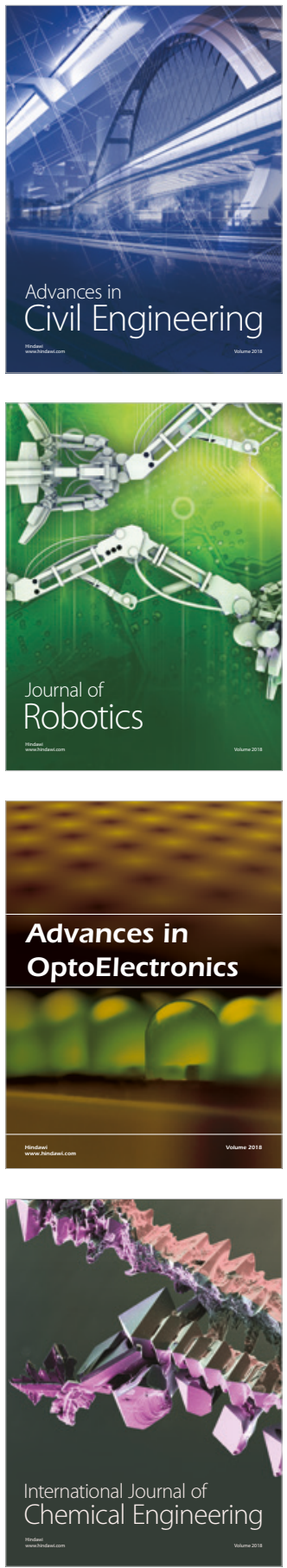

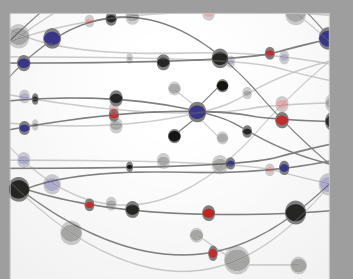

\section{Rotating \\ Machinery}

The Scientific World Journal

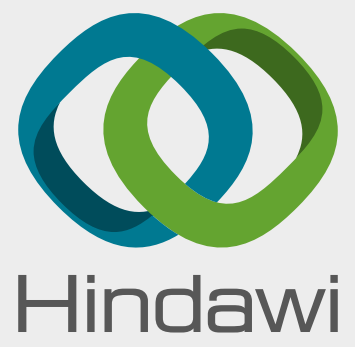

Submit your manuscripts at

www.hindawi.com
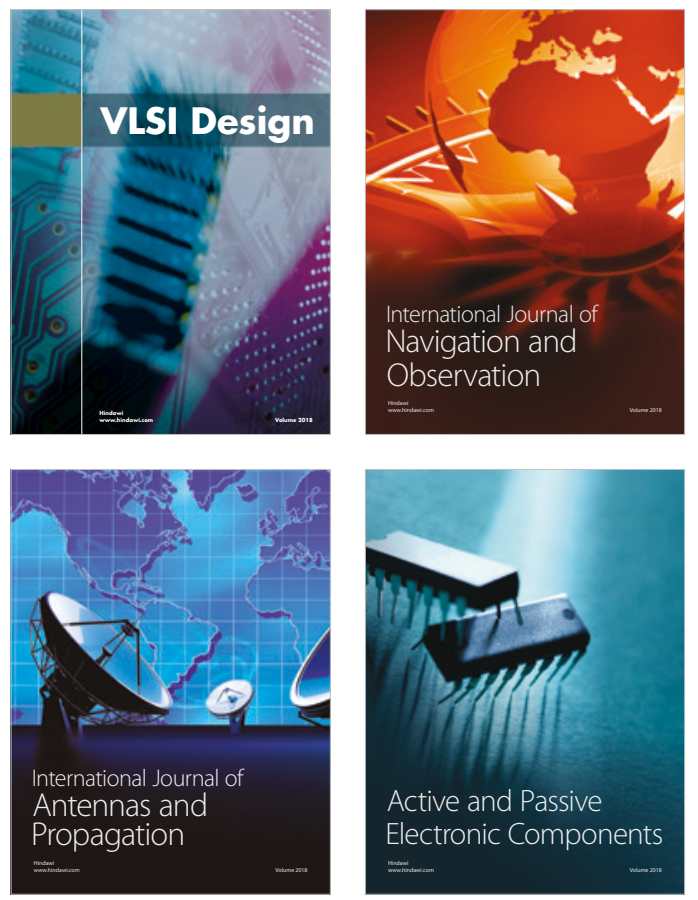
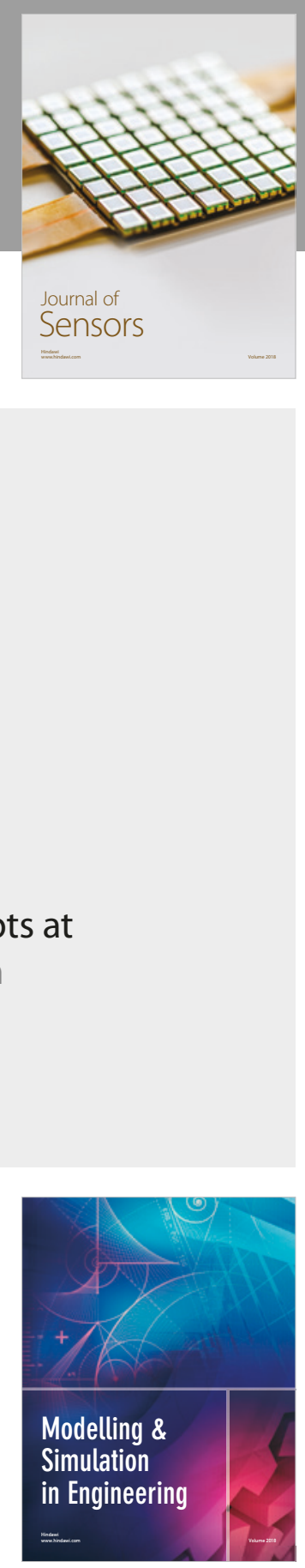

\section{Advances \\ Multimedia}
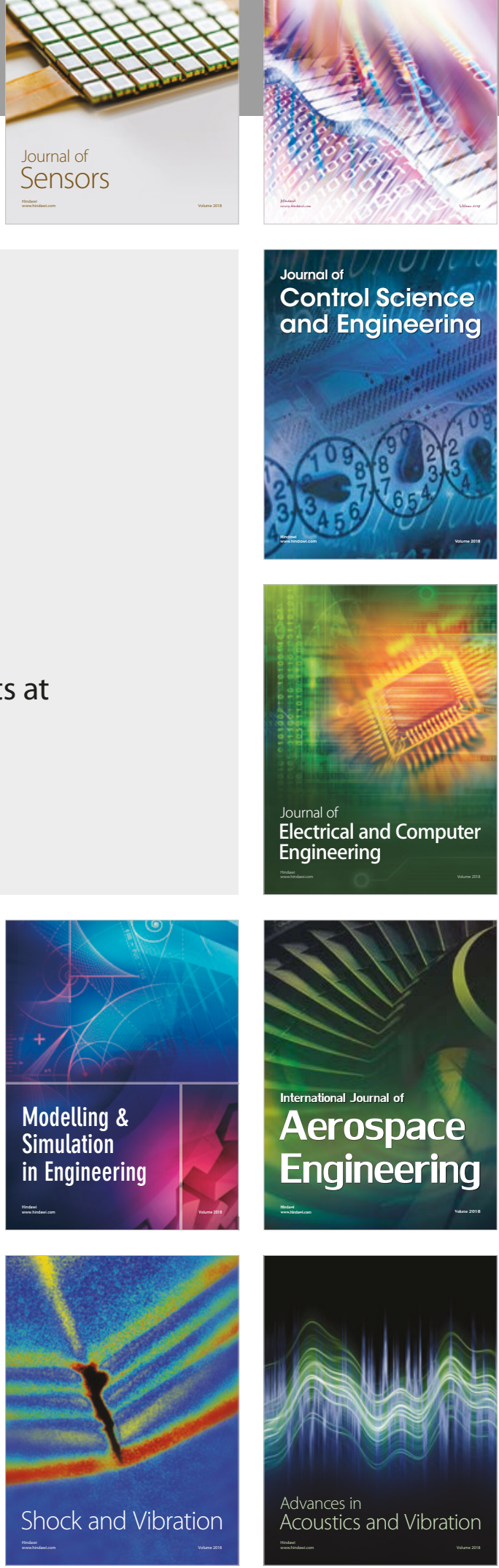